${ }^{6}$ Elliott HL, Dryburgh F, Fell GS, Sabet S, MacDougall AI. Aluminium toxicity during regular haemodialysis. Br Med f 1978;ii:1101-3.

${ }^{7}$ Berlyne GM, Ben-Ari J, Pest D, et al. Hyperaluminaemia for aluminium resins in renal failure. Lancet 1970;ii:494-6.

"Fleming LW, Stewart WK, Fell GS, Halls DJ. The effect of oral aluminium therapy on plasma aluminium levels in patients with chronic renal failure in an area with low water aluminium. Clin Nephrol 1982; $17: 222-7$

${ }^{9}$ Fisher RS. Sucralfate: a review of drug tolerance and safety. $\mathcal{F}$ Clin Gastroenterol $1981 ; 3$,suppl 2:181-4.

${ }^{10}$ Hollander D. Efficacy of sucralfate for duodenal ulcers: a multicenter, double-blind trial. $₹$ Clin Gastroenterol $1981 ; 3$,suppl 2:153-7.

${ }^{11}$ Kinoshita H, Kumaki K, Nakano H, et al. Plasma aluminium levels of patients on long term sucralfate therapy. Res Commun Chem Pathol Pharmacol 1982;35:515-7.

12 Gardiner PE, Ottaway JM, Fell GS, Halls DJ. Determination of alu- minium in blood plasma or serum by electrothermal atomic absorption spectrometry. Analytica Chimica Acta 1981;128:57-66.

${ }^{13}$ Kaehny WD, Hegg AP, Alfrey AC. Gastrointestinal absorption of aluminium from aluminium-containing antacids. New Engl $\mathcal{f} \mathrm{Med}$ $1977 ; 296: 1389-90$

14 Cumming AD, Simpson G, Bell D, Cowie J, Winney RJ. Acute aluminium intoxication in patients on continuous ambulatory peritoneal dialysis. Lancet $1982 ; \mathrm{i}: 103-4$.

15 Wolf A, Graf H, Pinggera WF, Stummvoli HK, Meisinger V. Serum aluminium and continuous ambulatory peritoneal dialysis. Ann Intern Med 1980;92:130-1.

${ }^{16}$ Nagashima R, Yoshida N. Sucralfate, a basic aluminium salt of sucrose sulphate. Arzneim Forsch 1980;30:73-80.

17 Spencer $\mathrm{H}$, Lender $M$. Adverse effects of aluminium-containing antacids on mineral metabolism. Gastroenterology 1979;76:603-6.

(Accepted 10 March 1983)

\title{
Sweat tests to diagnose cystic fibrosis in adults
}

\author{
MARGARET E HODSON, IRENE BELDON, RUTH POWER, FRANCIS R DUNCAN, \\ MAY BAMBER, J C BATTEN
}

\begin{abstract}
Twenty five patients with cystic fibrosis and 25 controls were studied to define a sweat sodium concentration in adults that could be taken as diagnostic of cystic fibrosis. Some of the controls had a sweat sodium concentration of over $50 \mathrm{mmol}(\mathrm{mEq}) / 1$, and thus cystic fibrosis should be diagnosed in an adult only when two measurements of sweat sodium concentration are above $70 \mathrm{mmol} / \mathrm{l}$. In cases in which the sweat sodium concentration was borderline a suppression test using fludrocortisone improved the accuracy of diagnosis; this test entails recording the lowest concentration reached after administration of the drug. A scatter diagram of the baseline sweat sodium concentrations plotted against the lowest concentration attained after suppression with fludrocortisone may aid the diagnosis further.
\end{abstract}

\section{Introduction}

The sweat test is accepted as an essential diagnostic test for cystic fibrosis in childhood. Normal adults have a higher sweat sodium concentration than normal children, and the test may therefore be less reliable in adults.' Di Sant'Agnese and Davis stated, however, that the criteria for diagnosing cystic fibrosis were similar in adults and children-namely, the presence of raised sweat chloride and sodium $(>50-60 \mathrm{mmol}(\mathrm{mEq}) / \mathrm{l})$ concentrations and either chronic pulmonary disease or pancreatic sufficiency." Shwachman et al commented that "one can interpret the sweat test in adults with the same degree of reliability as in children." 3 Modifications of the sweat test using aldosterone or fludrocortisone have been advocated. ${ }^{4} 5$ Most of these reports, however, concern children rather than

Brompton Hospital and Cardiothoracic Institute, London SW3 6HP MARGARET E HODSON, MD, MRCP, clinical senior lecturer in thoracic medicine and honorary consultant physician

IRENE BELDON, BSC, FIMLS, medical laboratory scientific officer

RUTH POWER, SRN, nursing sister, cystic fibrosis unit

FRANCIS R DUNCAN, SRN, clinical nurse specialist, cystic fibrosis unit MAY BAMBER, MB, MRCP, senior house officer

J C BATTEN, MD, FRCP, consultant physician

Correspondence to: $\mathrm{Dr} \mathrm{M}$ E Hodson, Cardiothoracic Institute, Fulham Road, London SW3 6HP. adults. The aim of the present study was to define a sweat sodium concentration in adults that could be taken as diagnostic of cystic fibrosis and to study the effect of fludrocortisone on sweat sodium concentrations in normal adults and adults with cystic fibrosis.

\section{Subjects and methods}

Sweat tests were performed on 25 patients with cystic fibrosis (10 male, 15 female; age range 15-36). The controls consisted of 25 fit adults (13 men, 12 women; age range 19-40). Sweat tests were performed using pilocarpine iontophoresis ${ }^{6}$ and the sodium concentration measured by flame photometry. All sweat tests were performed by a laboratory scientific officer or a nursing sister experienced in the technique. In each case over $100 \mathrm{mg}$ sweat was collected. Great care was taken that the filter paper was not contaminated by the investigator's sweat, and while sweat was being collected the filter paper was completely occluded by an airtight dressing to prevent loss of water by evaporation. All tests were performed in duplicate. Only duplicate readings that did not vary by more than $8 \mathrm{mmol} / \mathrm{l}$ were accepted.

Sweat tests were performed on day 1 . On days 2 and 3 all 50 subjects received $5 \mathrm{mg}$ fludrocortisone, and on days 4 and 5 the sweat tests were repeated. Fig 1 shows the results of the sweat tests over the five days in two controls and two patients with cystic fibrosis. The baseline value on day 1 and the lowest concentration reached on either day 4 or day 5 were recorded; the percentage suppression was calculated from these values. Statistical analysis was by discriminant analysis.?

\section{Results}

The mean $(2 \mathrm{SD})$ baseline sweat socium concentration was $43.20(+35 \cdot 3) \mathrm{mmol} / \mathrm{l}$ in the controls and $i(1) \cdot 1) 4(+31 \cdot 8) \mathrm{mmol} / \mathrm{l}$ in the patients with cystic fibrosis $(\mathrm{p}<0.001)$. Tinree of the 25 controls had concentrations of over $60 \mathrm{mmol} / \mathrm{l}$ (fig 2 , . The mean percentage suppression of sweat sodium concentration after administration of fludrocortisone was $26.32(.29 .9) \%$ in the controls and $8.08(+16.9) \%$ in the patients $(0.01>p>0.001)$ (fig 3). The mean of the iowest sweat sodium concentrations attained after suppression with fludrocortisone was $31.56(-27.5) \mathrm{mmol} / 1$ in the controls and $95 \cdot 6(-31 \cdot 3) \mathrm{mmol} / \mathrm{l}$ in the patients $(\mathrm{p}<0.001)$ (fig 4$)$. (No dup icate readings varied by more than $8 \mathrm{mmol} / \mathrm{l}$.)

Statistical analysis of the overlap between the distributions indicated that if a baseline sweat sodium concentration of above $60 \mathrm{mmol} / \mathrm{l}$ was regarded as being diagnostic of cystic fibrosis $17 \cdot 11 \%$ of controls and $0.34 \%$ of patients would be misclassified; and if $70 \mathrm{mmol} / \mathrm{l}$ was used $6.43 \%$ of controls and $1.88 \%$ of patients would 
be misclassified. The best cut off point from these data would be $73.12 \mathrm{mmol} / 1$, which would misclassify $3.75 \%$ of each group.

The percentage suppression of the sweat sodium concentrations was significantly less in the patients than the controls (fig 3). The overlap between the two populations, however, was considerable, so that this index is not useful in diagnosing cystic fibrosis.

After administration of fludrocortisone sweat sodium concentrations fell to below $70 \mathrm{mmol} / \mathrm{l}$ in all the controls (fig 4) but none of the patients. Statistical analysis showed that if concentrations remaining

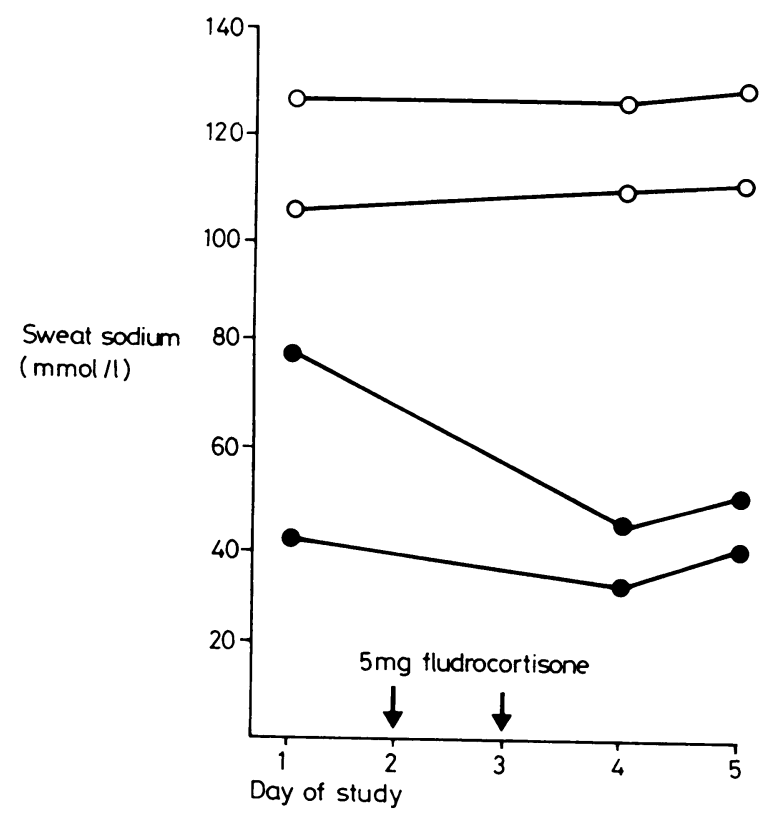

FIG 1 -Response of sweat sodium concentrations after $5 \mathrm{mg}$ fludrocortisone in two patients with cystic fibrosis $(\mathrm{O})$ and two controls (O).

Conversion: SI to traditional units-Sodium: $1 \mathrm{mmol} / \mathrm{l}=$ $1 \mathrm{mEq} / \mathrm{l}$.

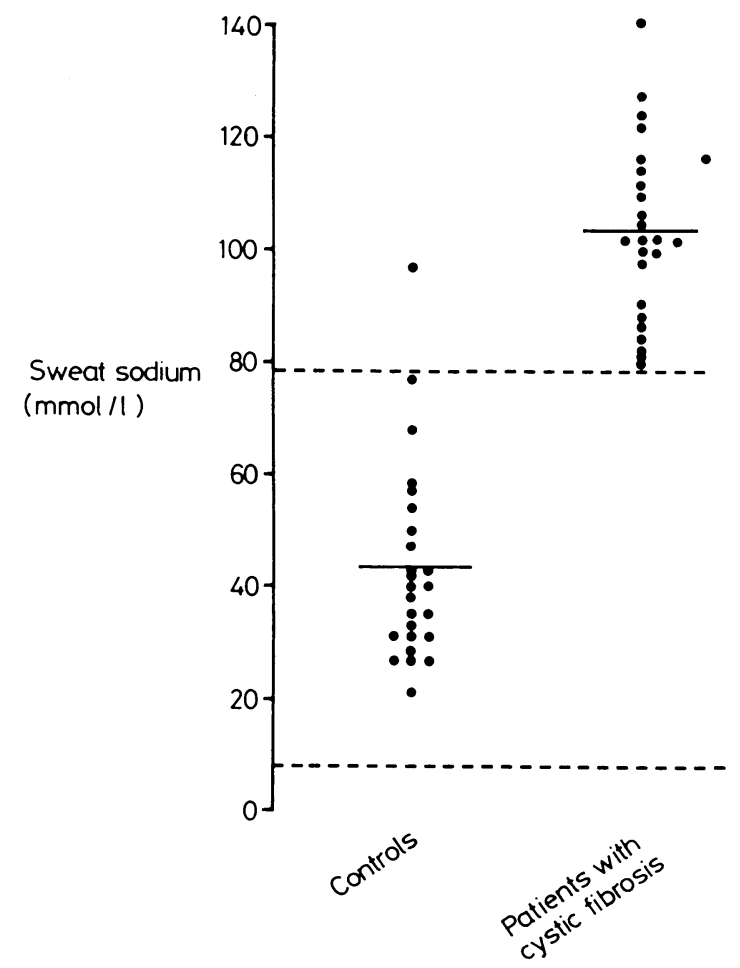

FIG 2-Sweat sodium concentrations in controls and adults with cystic fibrosis. Solid horizontal lines indicate means; broken horizontal lines indicate 2 SD for controls.

Conversion: $S I$ to traditional units-Sodium: $1 \mathrm{mmol} / \mathrm{l}=$ $1 \mathrm{mEq} / \mathrm{l}$.

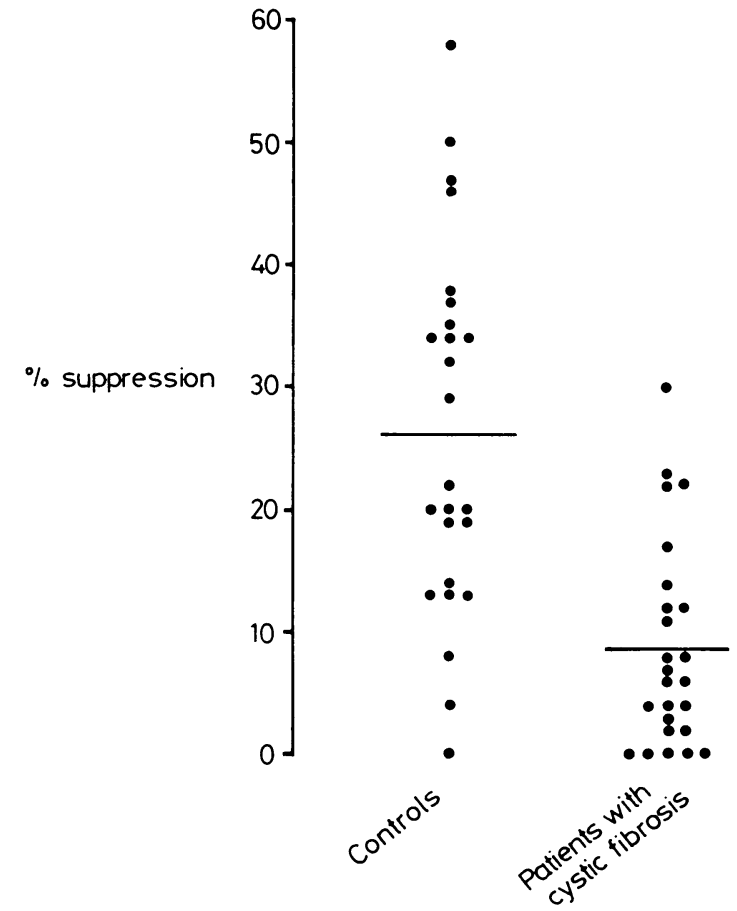

FIG 3-Percentage suppression of sweat sodium concentrations after administration of $5 \mathrm{mg}$ fludrocortisone in controls and patients with cystic fibrosis.

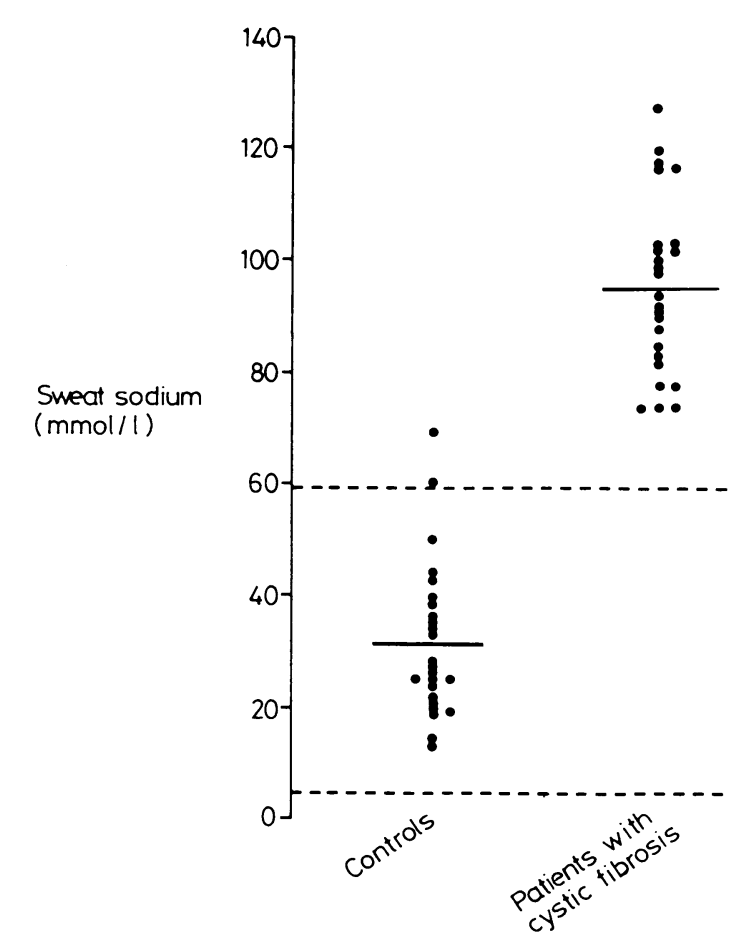

FIG 4-Suppression of sweat sodium concentrations after administration of $5 \mathrm{mg}$ fludrocortisone in controls and patients with cystic fibrosis. Solid horizontal lines indicate means; broken horizontal lines indicate 2 SD for controls.

Conversion: SI to traditional units-Sodium: $1 \mathrm{mmol} / \mathrm{l}-$ $1 \mathrm{mEq} / \mathrm{l}$.

above $63.58 \mathrm{mmol} / \mathrm{l}$ after suppression were taken as being diagnostic $\stackrel{\mathbb{2}}{\mathrm{Q}}$ of cystic fibrosis then $1.49 \%$ of controls and $1.49 \%$ of patients would $\bar{\gamma}$ be misclassified. A scatter diagram showing discriminant function $?$ was prepared (fig 5) from baseline sweat sodium concentrations and the lowest concentrations attained after suppression. By using both these variables only $1.46 \%$ of subjects in each group would be $\frac{\bar{Q}}{\partial}$ misclassified. 


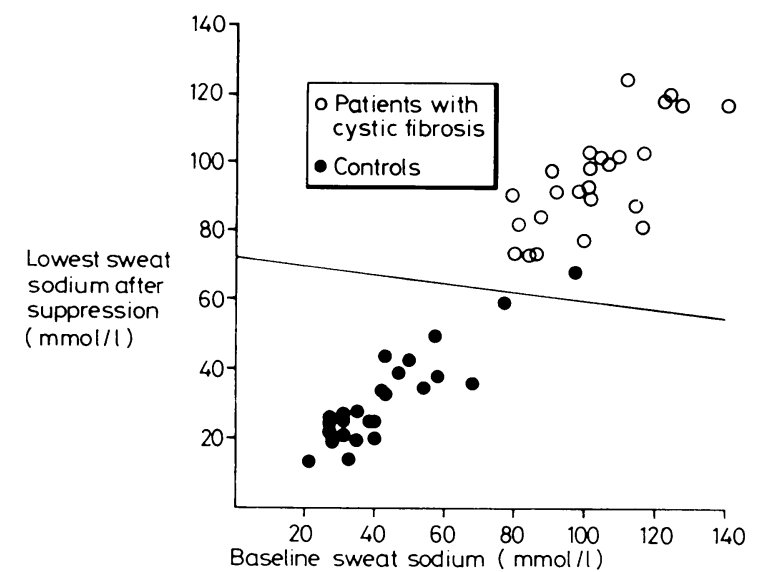

FIG 5-Baseline sweat sodium concentrations plotted against lowest concentration of sweat sodium recorded after suppression with fludrocortisone. The best discriminatory line between the two groups is shown.

Conversion: SI to traditional units-Sodium: $1 \mathrm{mmol} / \mathrm{l}=$ $1 \mathrm{mEq} / \mathrm{l}$.

\section{Discussion}

The baseline sweat sodium concentration remains a good discriminating test for cystic fibrosis in adults, but as concentrations of 50 and $60 \mathrm{mmol} / \mathrm{l}$ may be found in normal adults values below $70 \mathrm{mmol} / \mathrm{l}$ should not be taken as diagnostic of the disease. The percentage suppression of sweat sodium concentration after administration of fludrocortisone cannot be used as an accurate diagnostic test, but the lowest concentration reached after suppression distinguishes fairly accurately between normal subjects and adults with cystic fibrosis. In cases of doubt when a diagnosis of cystic fibrosis in an adult must be confirmed or refuted we suggest that both the baseline sweat sodium concentration and the lowest concentration to which the sweat sodium will be suppressed are estimated by a technician familiar with the technique. Fig 5 might usefully be used as a scatter diagram on which to plot individual results. Patients who fall below the best discriminatory line shown on fig 5 may be regarded as normal, while cystic fibrosis may be diagnosed with reasonable confidence in patients who fall above the line.

It is important that a diagnosis of cystic fibrosis is correct; false negative results may result in a patient not being given optimal treatment, and false positive results may cause unnecessary distress to both the patient and the family. Diagnosis of cystic fibrosis has genetic implications for the whole family as well as for the quality of life and life expectancy of the patient.

We are indebted to Miss M Rehahn for statistical analysis of these results and to Miss S Hockley for secretarial help.

\section{References}

1 McKendrick T. Sweat sodium levels in normal subjects, in fibrocystic patients and their relatives, and in chronic bronchitic patients. Lancet $1962 ; \mathrm{i}: 183-6$.

2 Sant'Agnese PA di, Davis PB. Cystic fibrosis in adults. Am F Med 1979; 66:121-32.

${ }^{3}$ Shwachman H, Kowalski M, Khaw KT. Cystic fibrosis: a new outlook. Medicine 1977;56:129-49.

4 Lobeck CC, McSherry MR. Response of sweat electrolyte concentrations to 9 alpha-fluorohydrocortisone in patients with cystic fibrosis and their families. F Pediatr 1963;62:393-8.

5 Siegenthaler P, de Haller J, de Haller R, Hampai A, Muller AF. Effect of experimental salt depletion and aldosterone load on sodium and chloride concentration in the sweat of patients with cystic fibrosis of the pancreas and of normal children. Arch Dis Child 1964;39:61-5.

6 Gibson LE, Cooke RE. A test for concentration of electrolytes in sweat in cystic fibrosis of the pancreas utilising pilocarpine by iontophoresis. Pediatrics $1959 ; 23: 545-9$.

${ }^{7}$ Armitage P. Statistical methods in medical research. Oxford: Blackwell, 1971:332-40.

(Accepted 1 February 1983)
ONE HUNDRED YEARS AGO We have received descriptive drawings and specifications of these tents, invented by Major Doecker of the Danish army, which are strongly recommended by the inventor for military use, in preference to the ordinary canvas marquees and tents employed by troops in the field, and to the wooden huts of standing camps. They are alleged to possess superior advantages from a sanitary point of view, and to be more economical in cost. The felt is fixed to suitably formed timber frames, and these are connected by hinged joints in such a way that the whole tent can be quickly erected at any given locality, and as rapidly displaced for removal. The tents are rectangular in form, and each has a case, which serves for keeping it together during transport, and for a table and cupboard for the reception of articles when the tent is in use. The chief sanitary advantages attributed to the felt tents, are the equable temperature maintained in them under varying conditions of the external atmosphere, their dryness, and the disinfecting qualities of the material. The felt being a bad conductor of heat, the interior of the tent is relatively cool under the rays of a powerful sun, and relatively warm at night, or in cold seasons. The material is impermeable to wet, so that the ground within is preserved in a dry state during rain. Ventilation is easily provided for, and regulated according to circumstances. Another stated advantage is that no vermin are found to harbour in these tents. The Doecker tents have been under trial for some years past, by the military and medical authorities in Copenhagen, and the results are said to have been so satisfactory under all circumstances, that the Danish Government has now definitely settled to adopt it throughout Denmark for army purposes. A hospital for the reception of cases of contagious disease, made of these felt huts, has also been recently constructed for the town of Copenhagen. For such a purpose as this, the felt huts, judging from the description, would appear to be particularly well fitted. Each hut can be dismounted in about ten minutes, and the material then admits of being thoroughly aerated, or, if necessary, washed with any disinfecting solution. As soon as they are dry they can be remounted for use in the same, or any other, suitable locality. They have thus obvious advantages over wooden huts, which are not only very permeable, from the nature of the material of which they are composed, but are also so fixed together that it is a matter of difficulty to take them to pieces, without, at the same time, destroying their fitness for further use. The question of substituting felt tents for the canvas tents in use in the British service, as of making any other important changes in the established articles of army equipment, is necessarily a serious one, as it entails, not merely considerations with regard to the articles themselves, but often affects various collateral subjects; as, for example, in the present case, the means of transport. Moreover, however well the felt tents may meet the wants of the Danish army, it by no means follows that they would answer the purposes of an army liable to be placed under such very different conditions of service as the widely distributed army of this country is. Three of the felt huts, one of them being designed for hospital purposes, are now being exhibited at Paris, from which place the description of them has been sent to us; and thus an opportunity is afforded, to those who may be interested in the subject, of making a thorough examination of them. Particulars in detail regarding them can be procured from the agents, Messieurs Hans Puggard, at 51, Rue Jean-Jacques-Rousseau, Paris. (British Medical fournal 1883;i:326.) 